\title{
ISSN (2503-4669)
}

(

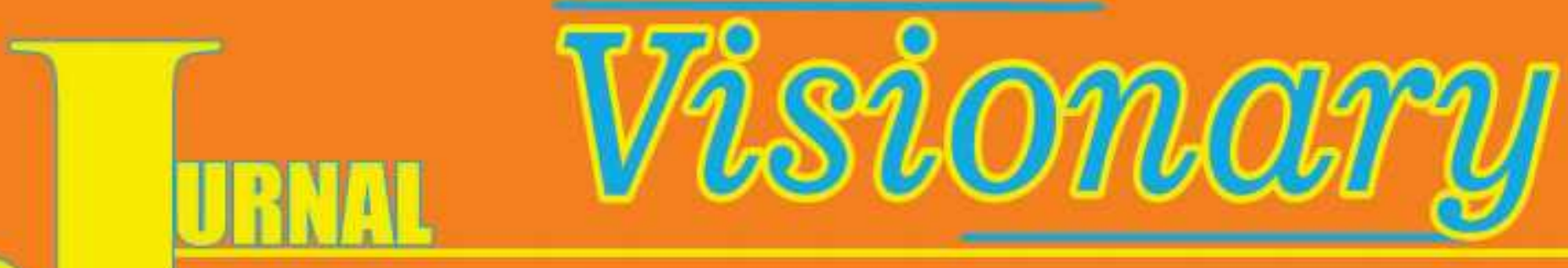

Penelitian dan Pengembangan di Bidang Administrasi Pendidikan

\begin{tabular}{|c|c|c|c|c|c|}
\hline $\begin{array}{c}\text { Jurnal } \\
\text { Visionary }\end{array}$ & Volume 6 & Nomor 2 & $\begin{array}{c}\text { Halaman } \\
65-118\end{array}$ & $\begin{array}{c}\text { Mataram Edisi } \\
\text { Oktober 2018 }\end{array}$ & $\begin{array}{c}\text { ISSN } \\
(2503-4669)\end{array}$ \\
\hline
\end{tabular}

Diterbitkan Oleh:

PRODI ADMINISTRASI PENDIDIKAN

FIP IKIP MATARAM 
Jurnal Vasionary

JURNAL VISIONARY

ADMINISTRASI PENDIDIKAN

Jurnal Penelitian dan Pengembangan di Bidang Administrasi Pendidikan

\section{Dewan Redaksi}

Pengarah

Penanggung Jawab

Ketua Penyunting

Sekertaris Penyunting

Penyunting Ahli
: 1. Drs. Wayan Tamba, M.Pd (Dekan FIP IKIP Mataram)

2. Suharyani, M.Pd. (Wadek I FIP IKIP Mataram)

3. Menik Aryani, MM (Wadek II FIP IKIP Mataram)

: Hardiansyah, S.Pd., MM (Ka. Prodi AP)

: Agus Fahmi, M.Pd

: Lu`luin Najwa, M.Pd

: 1. Prof. Dr. Udin Syaefudin Sa`ud, M.Pd (UPI Bandung)

2. Dr. Ir. Agustinus Hermino SP, M.Pd (Universitas Kanjuruhan Malang)

3. Dr. Zulfakar, M.Pd (IKIP Mataram)

Penyunting Pelaksana $\quad: \quad 1$. Ahmad Muslim, S.Pdi., M.Pd

2. Dr. M. Iqbal, M.Pd

3. M. Ari Irawan, M.Pd

Desain Cover $\quad$ : 1. Lukmanul Hakim, M.Pd

2. Rudi Hariawan, M.Pd

Sekretariat/Administrasi : Baiq Rohiyatun, M.Pd

Alamat Redaksi:

Redaksi Jurnal Visionary

Prodi Administrasi Pendidikan FIP IKIP Mataram

Gedung Dwitya, Lt.3. Jalan Pemuda No. 59 A Mataram

Telp.(0370) 638991

Email: ap_fip@ikipmataram.ac.id

Jurnal Visionary menerima naskah tulisan penulis yang original (belum pernah diterbitkan sebelumnya) dalam bentuk soft file, office word document (CD/ Flashdisk/ Email).

Diterbitkan Oleh: Prodi Administrasi Pendidikan FIP IKIP Mataram. 
Jurnal Vasionary

\section{JURNAL VISIONARY}

\section{ADMINISTRASI PENDIDIKAN}

Jurnal Penelitian dan Pengembangan di Bidang Administrasi Pendidikan

Daftar Isi

Halaman

Ahmad Muslim ${ }^{1}$ dan Nurjannah ${ }^{2}$

PENGGUNAAN MEDIA AUDIO VISUAL UNTUK MENINGKATKAN

HASIL BELAJAR FIQIH SISWA KELAS I MA NW NURUL IHSAN

TILAWAH LOMBOK TENGAH.

Dewi Rayani ${ }^{1}$ dan Wiwiek Zainal Sri Utami ${ }^{2}$

EFEKTIFITAS PEMANFAATAN MEDIA GAME DOBE FLASH

UNTUK MELATIH KEMAMPUAN INTERAKSI SISWA AUTISME

Zulfakar

MUTU DALAM LEMBAGA PENDIDIKAN ISLAM

Hardiansyah ${ }^{1}$ dan Agus Fahmi ${ }^{2}$

STRATEGI TATA KELOLA ADMINISTRASI PADA

PERGURUAN TINGGI BERBASIS ELECTRONIC RECORDS

$87-91$

Indri Susilawati ${ }^{1}$ dan Intan Primayanti ${ }^{2}$

PENGARUH LATIHAN DELORME TERHADAP PENINGKATAN

KEKUATAN OTOT QUADRICEPS PADA PEMAIN SEPAK BOLA

Lu'luinNajwa ${ }^{1}$ dan Nita Ade Kalista ${ }^{2}$

HUBUNGAN PERAN KEPALA SEKOLAH SEBAGAI KONSELOR

DENGAN ETOS KERJA GURU

Menik Aryani $^{1}$ dan Diah Lukitasari ${ }^{2}$

ANALISIS KINERJA KEUANGAN KOPERASI SYARIAH

PERMATA HIDAYATULLAH LOMBOK TIMUR $106-113$

Wiwien Kurniawati ${ }^{1}$ dan Muhtar Ahmad ${ }^{2}$

ANALISIS PEMBUATAN MEDIA PEMBELAJARAN DALAM MATA

KULIAH PENDIDIKAN MULTIMEDIA OLEH MAHASISWA

PRODI TEKNOLOGI PENDIDIKAN IKIP MATARAM 


\title{
STRATEGI TATA KELOLA ADMINISTRASI PADA PERGURUAN TINGGI BERBASIS ELECTRONIC RECORDS
}

\author{
Hardiansyah $^{1}$ dan Agus Fahmi ${ }^{2}$ \\ Prodi Administrasi Pendidikan, FIP IKIP Mataram \\ E-mail: hardiansyah@ikipmataram.ac.id
}

\begin{abstract}
Governance administration referred to in this research is how institutions organize, manage, and store data/records relating to the implementation of the administrative activities of Higher Education institutions, starting from the leadership down to the student level. The corporate governance is an activity that needs to be done effectively and efficiently in order to support productivity college. So far, the administration at the College still done conventionally. This is evident from the number of files and archives college piled up in the room and a filing cabinet. Thus, to find back the document that has been stored in cabinets require considerable time, besides that it must dismantle all the documents that have been previously arranged. The research method uses a qualitative approach, Draft Action Research utilizes quantitative data with qualitative data such as method mix focused on applied technology. Based on the research results obtained by the collected records in IKIP Mataram records are divided into several groups. By performing data reduction, grouping the records contained in the IKIP Mataram look that good governance based administration of electronic records has been applied properly. There are nine groups of records obtained in this study in which each group of records managed by each institution and the IKIP Mataram. Use of Electronic Records in the administration and other administrative activities at the IKIP Mataram very effective. All data on their activities and archives stored neatly in the respective chambers, structured data classification, and search data is quite efficient.Use of Electronic Records that can be controlled systematically to records from the time of creation or receipt, processing, distribution, organization, storage, retrieval up to destruction. Application of Electronic Records in higher education is relevant to the development and advancement of Science and Technology today, the program is a major concern so as to form a permanent administrative governance, especially at the IKIP Mataram.
\end{abstract}

\section{Keywords: Strategy, Governance, Electronic Records}

Abstrak: Tata kelola administrasi yang dimaksud dalam penelitian ini adalah cara lembaga mengatur, mengelola, dan menyimpan data/arsip yang berkaitan dengan pelaksanaan kegiatan administratif lembaga Perguruan Tinggi, mulai dari tingkat pimpinan sampai ke tingkat mahasiswa. Tata kelola tersebut merupakan kegiatan yang perlu dilakukan secara efektif dan efisien agar dapat menunjang produktivitas perguruan tinggi. Sejauh ini, pengelolaan administrasi di Perguruan Tinggi masih dilakukan secara konvensional. Hal ini terlihat dari banyaknya berkas dan arsip perguruan tinggi yang menumpuk di ruangan dan lemari arsip. Sehingga, untuk mencari kembali dokumen yang telah tersimpan di lemari membutuhkan waktu yang cukup lama, disamping itu harus membongkar semua dokumen yang sudah tersusun sebelumnya. Metode penelitian dilakukan menggunakan pendekatan kualitatif, kemudian dirangkaikan dengan Rancangan Penelitian Tindakan (Action Research) ini memanfaatkan data kuantitatif dengan data kualitatif seperti metode campuran yang terfokus pada terapan teknologi. Berdasarkan hasil penelitian maka diperoleh rekod terkoleksi di IKIP Mataram terbagi dalam beberapa kelompok rekod. Dengan melakukan reduksi data, pengelompokan rekod yang ada di IKIP Mataram terlihat bahwa tata kelola administrasi berbasis electronic record sudah diterapkan dengan baik. Terdapat 9 kelompok rekod yang 
diperoleh dalam penelitian ini dimana setiap kelompok rekod dikelola oleh masing-masing Lembaga dan Biro yang ada di IKIP Mataram. Penggunaan Electronic Records dalam tata kelola administrasi maupun kegiatan administratif lainnya di IKIP Mataram sangat efektif. Seluruh data hasil kegiatan dan arsip tersimpan secara rapi dalam biliknya masing-masing, klasifikasi data tertata, dan pencarian data cukup efisien. Penggunaan Electronic Records yang dapat terkontrol secara sistematis terhadap arsip dinamis sejak saat penciptaan atau penerimaan, pengolahan, distribusi, penataan, penyimpanan, temu balik sampai dengan pemusnahannya. Penerapan Electronic Records pada perguruan tinggi cukup relevan dengan perkembangan dan kemajuan Ilmu Pengetahuan dan Teknologi saat ini, program tersebut menjadi perhatian utama sehingga menjadi bentuk tata kelola administratif secara permanen khususnya di IKIP Mataram.

Kata kunci: Strategi, Tata Kelola, Electronic Records

\section{LATAR BELAKANG}

Sistem pendidikan memiliki suatu kegiatan administratif yang disebut dengan pengelolaan atau manajemen. Dalam kegiatan pendidikan terdapat suatu organisasi yang bertugas mengelola atau memanajemenkan suatu kegiatan dengan harapan dapat mencapai tujuan tertentu. Tata Kelola Administrasi merupakan kegiatan yang perlu dilakukan secara efektif dan efisien agar dapat menunjang produktivitas perguruan tinggi. Baik buruknya kualitas pendidikan tergantung dari baik tidaknya kegiatan pengelolaan atau manajemen yang dilakukan oleh setiap anggota organisasi.

Pengelolaan administrasi di perguruan tinggi pada umumnya masih dilakukan secara konvensional. Hal ini terbukti dengan banyaknya berkas dan arsip perguruan tinggi yang menumpuk di ruangan dan lemari arsip. Sehingga untuk mencari kembali dokumen membutuhkan waktu yang lama dan harus membongkar semua dokumen yang sudah tersusun sebelumnya. Berhasil atau tidaknya suatu kegiatan tergantung dari bagaimana sistem pengelolaan yang dilakukan dalam kegiatan tersebut, maka dari itu pengelolaan atau manajemen dalam suatu kegiatan terutama dalam bidang pendidikan sangat dibutuhkan untuk mewujudkan segala tujuan-tujuan dalam pendidikan nasional.

Karena itu maka penting untuk dilakukan pengkajian dan perubahan sistem dalam pengelolaan administrasi perguruan tinggi menjadi lebih praktis dan lebih terbaharukan dengan menggunakan Electronic Recods. Penggunaan Elektronic Records yang dapat terkontrol secara sistematis terhadap arsip dinamis sejak saat penciptaan atau penerimaan, pengolahan, distribusi, penataan, penyimpanan, temu balik sampai dengan pemusnahannya. Elektronik Recordsebagai keluaran fisik dari komputer. Menurut National Archives and Records Administration (NARA), elektronik merupakan arsip-arsip yang disimpan dan diolah dalam suatu format, dimana hanya komputer yang dapat memprosesnya.Sehingga mengurangi penumpukan dokumen dalam ruangan serta mempermudah dalam proses pencarian data tanpa harus membongkar dokumen lama. Berdasarkan rangkaian latar belakang permasalahan di ataspeneliti terdorong untuk melakukan penelitian tentang: "Strategi Tata Kelola Administrasi Pada Perguruan Tinggi Berbasis Electronic Records".

\section{METODE PENELITIAN}

Penelitian ini berupaya mengungkap tentang strategi tata kelola administrasi pada perguruan tinggi berbasis Electronic Records. Metode penelitian yang digunakan pada penelitian ini adalah metode penelitian kualitatif yaitu pendekatan yang temuantemuan penelitiannya tidak diperoleh melalui prosedur statistik atau bentuk perhitungan lainnya. Prosedur ini menghasilkan temuan-temuan yang diperoleh dari data-data yang dikumpulkan dengan menggunakan beragam sarana 
meliputi pengamatan dan wawancara, namun bisa juga mencakup dokumen, buku, kaset video, dan bahkan data yang telah dihitung untuk tujuan lain misalnya data sensus.

Dalam penelitian kualitatif langkahlangkah/tahap-tahapan itu secara garis besar dibagi kedalam tiga bagian, yaitu; 1) Tahapan persiapan/pra-lapangan, 2) Tahapan pekerjaan lapangan, dan 3) Tahapan analisis data. Metode kualitatif memiliki prosedur penelitian untuk menghasilkan data deskriptif berupa kata tertulis atau lisan dari orang dari prilaku yang diamati melalui prosedur penelitian kualitatif yaitu: (a) penetapan informan kunci yakni civitas akademik dalam hal ini rektor, wakil rektor, kepala biro, dekan, dan ketua program studi yang ada di kampus IKIP Mataram. (b) melakukan penelusuran data lapangan dengan cara observasi/pengamatan, wawancara, dan studi dokumentasi terkait rumusan penelitian, (c) menganalisis data dengan cara mengaudit data, pemberian nomor dan kode data, menganalisis makna data, melakukan pengecekan kembali kebenaran data kepada informan (member check), melakukan konfirmasi data atau pengecekan data melalui sumber informasi terkait lainnya dalam bentuk triangulasi, (d) melakukan penayangan data (display data), (e) penarikan kesimpulan sementara dalam bentuk proporsi temuan penelitian, dan (f) penetapan kesimpulan, implikasi dan rekomendasi hasil penelitian

\section{HASIL DAN PEMBAHASAN}

Hasil Penelitian

Untuk memenuhi kualitas proses akademik, setiap Program Studi saat ini telah memiliki dosen berkualifikasi Magister dan Doktor, sebagian besar Dosen tersebut merupakan Dosen Tetap Yayasan Pembina IKIP Mataram. Selain Dosen Tetap Yayasan, IKIP Mataram juga memiliki Dosen Kopertis Dipekerjakan, Dosen Luar Biasa dan Dosen Tamu yang juga memberikan peran sangat penting bagi terselenggaranya proses akademik yang berkualitas di IKIP Mataram. Rekod yang terkoleksi di IKIP Mataram dikelompokkan sebagai berikut.

Tabel 01. Electronic Rekod IKIP Mataram

\begin{tabular}{|c|c|c|}
\hline No. & Kelompok & Rekod Terkoleksi \\
\hline 1. & Rekod administratif & $\begin{array}{l}>\text { Statuta IKIP Mataram, } \\
>\underline{\text { SOTK IKIP Mataram, }}, \\
>\text { Renstra IKIP Mataram, } \\
>\text { Renop IKIP Mataram, } \\
>\text { Pedoman BKD IKIP Mataram 2018, } \\
>\text { Pedoman Penilaian Jafung Dosen } \\
>\text { Buku Pedoman Pendidikan IKIP Mataram, } \\
>\text { Kalender Akademik Tahun Akademik 2017/2018, } \\
>\text { Pedoman Administrasi Persuratan IKIP Mataram, } \\
>\text { Layanan Administrasi Akademik, } \\
>\text { Pedoman Kerjasama, } \\
>\text { Panduan Mahasiswa Baru Tahun 2018, } \\
>\text { Pedoman Organisasi Mahasiswa. }\end{array}$ \\
\hline 2. & Rekod Kepegawaian & $>$ Data Dosen Se-IKIP Mataram \\
\hline 3. & $\begin{array}{l}\text { Rekod Sarana Dan } \\
\text { Prasarana Pendidikan }\end{array}$ & $\begin{array}{l}\text { a. Sarana dan Prasarana Akademik terdiri atas: } \\
\text { Sarana dan Prasarana Akademik Umum : 1) } \\
\text { Sarana dan prasarana kuliah, 2) Sarana dan } \\
\text { prasarana perpustakaan, 3) Sarana teknologi } \\
\text { informasi dan komunikasi (TIK), 4) Sarana dan }\end{array}$ \\
\hline
\end{tabular}


IKIP Mataram telah berhasil menerapkan strategi tata kelola administrasi berbasis electronic record. Hal tersebut dapat dilihat melalui keseriusan sivitas kampus dalam mengelola websitenya (www.ikipmataram.ac.ad), dapat dilihat dari banyaknya data yang terekod secara online.

\section{KESIMPULAN}

1. Tata kelola administrasi berbasis electronic record di IKIP Mataram sudah diterapkan dengan baik.

2. Terdapat 9 kelompok rekod yang dimana setiap kelompok rekod dikelola oleh masing-masing Lembaga dan Biro yang ada di IKIP Mataram.

3. Rekod yang telah diterapkan di kampus IKIP Mataram masih pada siklus penciptaan, distribusi, penggunaan, dan pemeliharaan/penyimpanan rekod aktif. Masih terdapat empat siklus yang belum diterapkan di IKIP Mataram diantaranya siklus pemindahan data, penyimpanan rekod inaktif, pemusnahan data, dan penyimpanan data permanen.

4. IKIP Mataram telah berhasil menerapkan strategi tata kelola administrasi berbasis electronic record yang dapat dilihat melalui keseriusan sivitas kampus dalam mengelola websitenya (www.ikipmataram.ac.ad).

\section{DAFTAR PUSTAKA}

Adikara, Fransiskus. 2013. Implementasi Tata Kelola Teknologi Informasi Perguruan Tinggi Berdasarkan COBIT 5 pada Laboratorium Rekayasa
Perangkat Lunak Universitas Esa Unggul. Prosiding Seminar Nasional Sistem Informasi Indonesia (SESINDO), 131 - 136.

Engkoswara, dkk. 2010. Administrasi Pendidikan. Bandung: Alfabeta.

Fitroh. 2012. Penilaian Tingkat Kematangan Tata Kelola TI pada Sistem Informasi Manajemen Akademik. Seminar Nasional Aplikasi Teknologi Informasi 2012 (SNATI 2012).

H. Gunawan Ary, 2011. Administrasi Pendidikan Mikro. Jakarta : Rineka Cipta.

Indrajit, R. Eko dan Djokopranoto, R. (2006). Manajemen Perguruan Tinggi Modern. Yogyakarta : Andi

Mirmani, Anon. (2005). Proses Analisis Kegiatan Untuk Membangun Klasifikasi Dokumen Di Perguruan Tinggi. Jurnal Ilmu Informasi, Perpustakaan dan Kearsipan Vol.1.No.2, Juni 2005.

Sugiarto, Agus dan Wahyono, Teguh (2005). Manajemen Kearsipan Modern : Dari Konvensional Ke Basis Komputer. Yogyakarta : Penerbit GavaMedia.

Sulistyo-Basuki.(2003). Manajemen Arsip Dinamis : Pengantar, Memahami dan mengelola Informasi dan dokumen. Jakata : Gramedia Pustaka Utama 


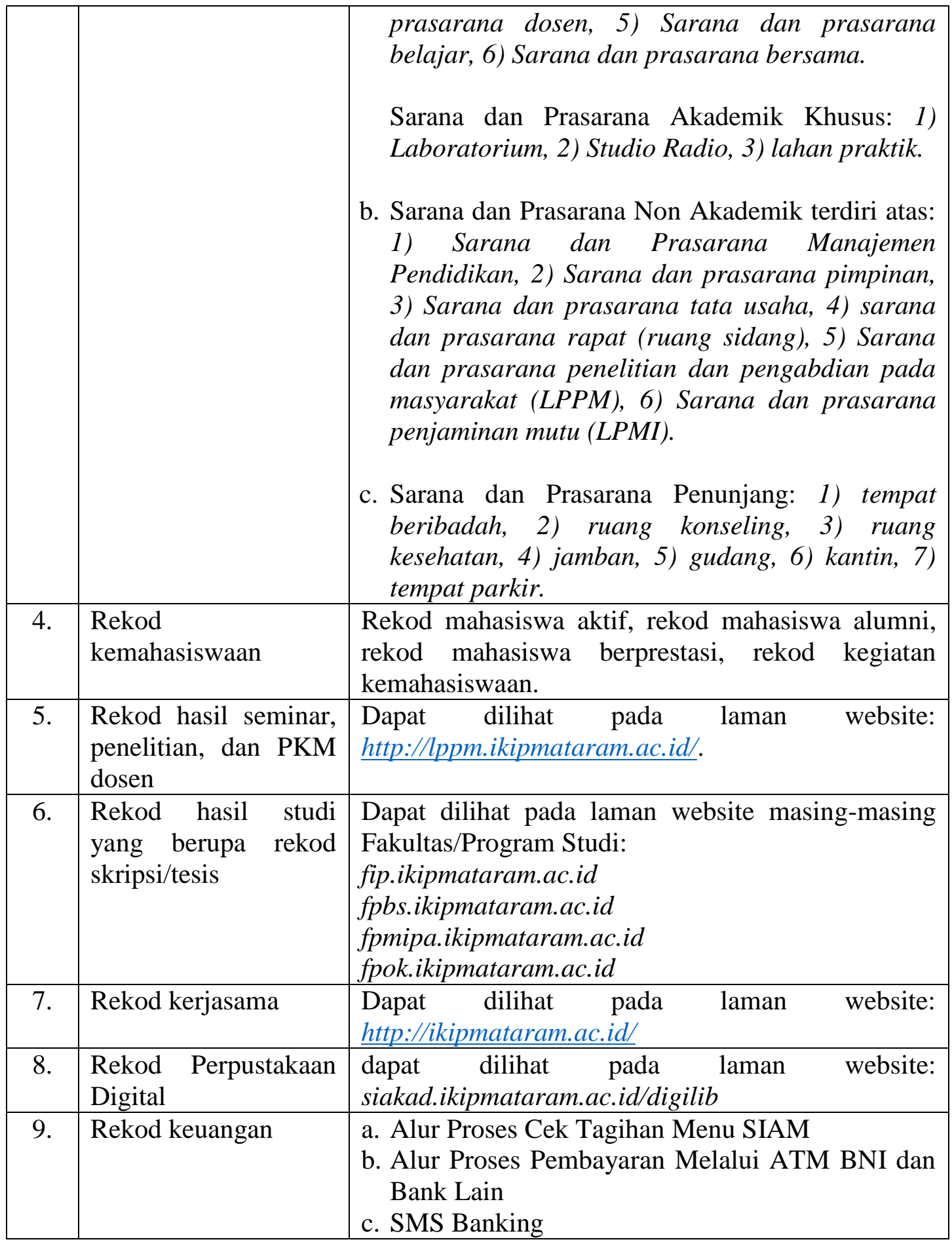

\section{PEMBAHASAN}

Berdasarkan hasil pengelompokan rekod yang ada di IKIP Mataram dengan melakukan reduksi data terlihat bahwa tata kelola administrasi berbasis electronic record sudah diterapkan dengan baik. Terdapat 9 kelompok rekod yang diperoleh dalam penelitian ini dimana setiap kelompok rekod dikelola oleh masing-masing Lembaga dan Biro yang ada di IKIP
Mataram. Namun rekod yang telah diterapkan di kampus IKIP Mataram masih pada siklus penciptaan, distribusi, penggunaan, dan pemeliharaan / penyimpanan rekod aktif. Masih terdapat empat siklus yang belum diterapkan di IKIP Mataram diantaranya siklus pemindahan data, penyimpanan rekod inaktif, pemusnahan data, dan penyimpanan data permanen. Meskipun demikian, kampus 


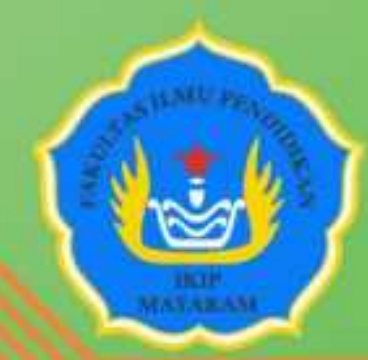

Soltarotsuntiafts

Program Studi Administrasi Pendidikan FIP IKIP MATARAM

J1. Pemuda No. 59 A Mataram

Website: www.fip.ikipmataram.ac.id

Email:ap_fip@ikipmataram.ac.id

Telp. (0370) 638991

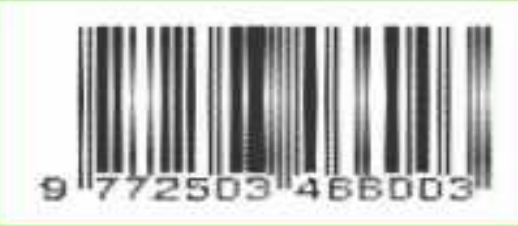

